\title{
Is There Any Asymmetry Between Wholesale and Consumer Food Prices in Selected European Countries and Turkey?
}

\author{
Ozge Kandemir Kocaaslan ${ }^{\mathrm{a}}$, Abdurrahman Nazif Catik ${ }^{\mathrm{b}}$, Ali Kat ${ }^{\mathrm{c}}$
}

\begin{abstract}
Vertical price linkages (transmission mechanism) constitute an important pillar of food and agricultural economics research. These linkages contain information on the relationships between the economic units of the supply chain at different levels. This study aims to investigate the existence of an imperfect price transmission mechanism in the food markets of the selected countries between January 2000 and January 2018. For this purpose, the transmission mechanism between producer and consumer prices in the food supply chain is analyzed via a nonlinear autoregressive distributed lag model (NARDL). The results show that asymmetric price transmission is not a market anomaly, but it is a common situation in the market. The results imply that the presence of asymmetric price transmission in the food market might trigger inequalities by mainly decreasing the income of the lower-income groups.
\end{abstract}

\author{
Keywords: Food Price, \\ Wholesale Prices, Consumer \\ Prices, Price Transmission \\ Mechanism, Asymmetry \\ JEL: C22, C51, E31 \\ Received : 15 March 2021 \\ Revised : 11 May 2021 \\ Accepted : 28 June 2021 \\ Type : Research
}

\section{Introduction}

Following the global food crises of 2007 and 2008, food prices, volatility in food prices, and food security have been among the top policy priorities for both national policymakers and international organizations in the last decade (OECD, 2015). Since the food crisis, recent developments in the level of food prices have sparked the interest of researchers and policymakers attempting to understand the underlying reasons of how prices are shaped and transmitted along the distribution chain.

A common criticism of the final consumers in the context of food prices is that; while an increase in input costs is immediately transmitted to the consumer prices in the market, cost decreases are not transmitted to the consumer prices at the same speed and magnitude. Peltzman (2000) defines this situation as a common rule of the market rather than an anomaly randomly detected in the market. Vertical price transmission throughout the supply chain is expressed as the response of prices at one level of the chain to the price changes at another level (Goodwin \& Vavra, 2005). However, the price change occurring at one level of the chain may not always be transmitted to other levels. This phenomenon, known as asymmetric or imperfect price transmission, is crucial since it may indicate a potential flaw in the market (European Commission, 2012).

Some studies have attempted to discover the potential causes of asymmetry in the transmission channel. Goodwin and Vavra (2005) classified these factors into four categories: sticky prices, inventory

\footnotetext{
a Assoc. Prof., PhD., Hacettepe University, Faculty of Economics and Administrative Sciences, Department of Economics, Ankara, Turkiye, ozge.kandemir@hacettepe.edu.tr (ORCID ID: 0000-0003-4159-3204)

b Assoc. Prof., PhD., Ege University, Faculty of Economics and Administrative Sciences, Department of Economics, Izmir, Turkiye, a.nazif.catik@ege.edu.tr (ORCID ID: 0000-0001-9247-5668)

PhD., The Ministry of Industry and Technology, Ankara, Turkiye, alikat.uab@gmail.com (ORCID ID: 0000-0003-0129-682X)
} 
management strategies, policy intervention, and market failures (market power). Among these, market failures have been identified as the primary cause of asymmetric price transmission. According to this point of view, the food and agriculture markets have an oligopolistic structure. Meyer and Von Cramon-Taubadel (2004) contend that, in addition to market power, factors such as adjustment (menu) costs, product storage, and perishability, and pricing policies (e.g., price bases) may generate an asymmetric price mechanism.

There is an inverse relationship between income level and the portion of income spent on food. In developed countries, consumers spend a relatively small part of their disposable income on food. However, even in developed countries, the lowest income group of the population allocates a relatively higher portion of their disposable personal income to food expenditures (OECD, 2014). Welfare losses caused by asymmetric price transmission mechanisms often work against consumers. In markets where positive asymmetries occur, higher consumer prices are observed compared to the situation where this asymmetry is not present (Meyer \& von Cramon-Taubadel, 2004). Positive asymmetries affect each consumer differently, depending on the income level of the consumer. If a product with positive asymmetry is consumed more intensely by lowerincome groups, this income group is exposed to more welfare losses than other income groups. Because the group with the highest share spent on food in disposable personal income is the lower-income groups (OECD, 2014).

In this context, the main objective of the study is to investigate the existence of an asymmetric price transmission mechanism in European Union (EU) countries (Italy, Spain, the Netherlands, and Poland) and Turkey. Our study aims to contribute to the existing literature on the analysis of food price transmission channels in two aspects. First, to our knowledge, there is no study investigating the differences among the food price transmission channels of the EU countries and Turkey. Second, the literature review also points out that the recently introduced nonlinear autoregressive distributed lag (NARDL) cointegration model has not been applied to account for the possible asymmetry in the transmission channel between wholesale and consumer food prices for the countries under consideration. NARDL methodology is adopted among the other alternative asymmetric specifications since it allows the analysis of the asymmetric price transmission mechanism in both the long and short run.

The remainder of the article is structured as follows. The literature review discussing the results of the studies on asymmetric price transmission mechanisms is presented in section two. Section 3 describes the food price data utilized in the study. Section four presents the estimation results of the NARDL model. Finally, the paper ends with concluding remarks based on the empirical findings.

\section{Literature Review}

For nearly a half-century, agricultural economists have focused their attention on price transmission mechanisms. It is unsurprising given that the size and pace at which shocks are moved from one stage to the next in a market have significant policy consequences and welfare effects (Fousekis, Katrakilidis, \& Trachanas, 2016). Many empirical studies on asymmetric price transmission in commodity markets have been conducted as a result of the increasing disparity between farm, output, and retail prices.

A possible asymmetry in the price transmission channel is taken into account by introducing asymmetric transformation of the variables to the model or using various econometric methodologies. First studies have adopted pre-integration techniques to analyze the asymmetric price transmission. Tweeten and Quance (1969), for example, show that the supply elasticity parameter for aggregate farm output is greater in the long run, and it varies depending on whether prices are falling or rising. According to Wolffram (1971), the decomposition method in Tweeten and Quance's (1969) method can result in inaccurate parameter estimates. Houck (1977) demonstrates that when a variable is segmented into decreasing and increasing components, it is highly likely that each of the two components will interact with the other in the model, which is aligned with Wolffram's (1971) methodology. The findings also indicate that the estimated price elasticities in milk and pinto bean supply functions are very similar and close to one for both falling and rising prices. 
Ward (1982) investigates price transmission for a sample of fresh vegetables using Wolffram's (1971) price transmission procedure and a distributed lag model. According to the findings, both shipping point and retail prices tend to lag changes in wholesale prices. Ward (1982) demonstrates that price changes for this subset of fresh vegetables are not disseminated in the same period. Furthermore, it has been discovered that retail prices adapt to lower wholesale prices, whereas increases in wholesale prices are not fully transmitted at retail prices. Using a similar model to Ward (1982), Boyd and Brorsen (1988) demonstrate that the response of wholesale prices to farm price increases and decreases in the US pork markets is identical. Furthermore, there is a significant difference in retailers' reactions to wholesale price decreases and increases.

More recent studies have used cointegration methodologies to avoid the possibility of spurious regression issues and the lack of related information about common price patterns. Von Cramon-Taubadel and Fahlbusch (1994) conducted the first study on asymmetric price transmission using cointegration methods. They suggested using an error correction model (ECM) modified with asymmetric adjustment components to test the asymmetry in the price transmission between cointegrated price series. Based on this specification, they find little evidence of asymmetric transmission in the global wheat market. Varga (2007) investigates vertical price transmission in eighteen commercial food product chains for Hungary using monthly data covering the period between 2001 and 2005. The results based on the estimation of ECM methodology show a significant product variation in market dominance for the entire industry. However, the variation is not significantly related to any specific sectors or vertical levels. Barassi and Ghoshray (2007) examine the long-run relation between US and EU wheat export prices for the period 1981-2000 with the VECM approach. They find a structural break in the long-run relationship after 1992 associated with CAP reforms. Subsample estimates do not support any significant long-run relationship prior to the 1992 CAP reform, but significant evidence of cointegration is reported after the reforms are implemented. Gómez and Koerner (2009) study the asymmetric price transmission between retail and international coffee prices in the United States, France, and Germany. The evidence on the various price transmission mechanisms suggests that there are significant differences between countries in terms of market structure and market performance.

Using both the method of Houck (1977) and the error correction model specification of von CramonTaubadel and Loy (1996), Capps and Sherwell (2005) estimate the long-run and short-run elasticities of price transmission between the retail and farm levels of the marketing chain for milk for seven US cities. Retail level milk prices are found to adjust more moderately to the falls in milk prices and faster to the rises in the farm level milk prices using ECM. In both approaches, price transmission elasticities are more prominent in rising farm-level prices than the related elasticities in the case of falling farm-level prices.

Some recent studies have also attempted to analyze the significance of asymmetries in the transmission channel by using threshold ECMs. Threshold effects may arise when the larger shocks lead to a different outcome than smaller shocks. By utilizing a threshold cointegration model, Goodwin and Harper (2000) find evidence on the unidirectional transmission of shocks running from the farm, to wholesale, to retail markets but not in the reverse direction in the US pork market. Goodwin and Piggott (2001) examine price dynamics in the soybean and corn markets of North Carolina with a threshold vector error correction model (TVECM) and provide evidence in favor of significant threshold effects. Employing threshold cointegration tests, Abdulai (2002) examines the link between retail and producer pork prices in Switzerland and finds that the price transmission in the market is subject to asymmetric behavior. Ghoshray (2002) investigates the price differentials in pairs for the international wheat market with the threshold autoregressive (TAR) and momentum TAR (M-TAR) methodologies. The empirical results indicate that the global wheat market is deeply integrated; hence there is little evidence of asymmetry. Using monthly maize, wheat, and soya prices in the US, Argentina, and Brazil, Balcombe, Bailey, and Brooks (2007) corroborate the evidence on the threshold effects in the price transmission channel. Ben-Kaabia and Gil (2007) examine the retail and farm prices in the lamb sector in Spain with a three-regime TAR. Their results show that price transmission is perfect in the long run in the sense that any demand or supply shocks are completely reflected 
through the market chain. However, the presence of an asymmetric price adjustment mechanism between the retail and farm levels in the short run implies that retailers might gain from rising marketing margins.

Awokuse and Wang (2009) use TAR models to investigate asymmetric price transmission for three dairy products in the United States. Their findings show that there is an asymmetry in price transmission between the retail and producer levels in fluid milk and butter, but not in cheese. They also emphasize that ignorance of asymmetry and threshold effects may have led to inaccurate inferences about the variables' long-run relationship. Rezitis and Stavropoulos (2011) investigate the nonlinear price adjustments and volatility in the Greek broiler sector using a threshold VECM and two multivariate GARCH models. They reject the null of linear cointegration in favor of a three-regime threshold cointegration model. Multivariate GARCH estimates further imply the existence of a significant persistence in both consumer and producer broiler prices.

In this study, we employ the Nonlinear ARDL (NARDL) cointegration approach proposed by Shin, Yu, and Greenwood-Nimmo (2014) to examine the asymmetric price transmission mechanism in the food market. Shin et al. (2014) stated there are numerous advantages of the NARDL model over the other alternative asymmetric methodologies utilized in the literature. First, similar to the ARDL, this methodology does not necessitate that the variables under consideration have the same order of integration. Second, the flexible structure of the model allows us to instantaneously deal with the non-stationarity and the nonlinearity of the variables. Finally, the decomposition of the variables into partial sums of positive and negative changes also allows us to separate asymmetric price transmission in magnitude from asymmetric price transmission in speed. As a result, the model can account for the effects of asymmetry in both the long and short run.

In the literature, studies using NARDL models have usually focused on themes such as the inflationary effects of energy prices (e.g. Greenwood-Nimmo \& Shin, 2013a), exchange rates (e.g. Delatte \& LopezVillavicencio, 2012), and house prices (e.g. Katrakilidis \& Trachanas, 2012). However, research on horizontal and vertical price transmission and asymmetry in food markets has been sparse. To the best of our knowledge, no research has been conducted on the asymmetric price transmission mechanism between producer and consumer prices in the food supply chain utilizing NARDL methodology. We came across only one study, Fousekis et al. (2016), using NARDL to analyze asymmetric price transmission channels in the food market. However, their study is country-specific and examines only the vertical price transmission in the US beef sector. Their findings show that there is an asymmetry in magnitude for the farm level and wholesale prices and asymmetry in magnitude and asymmetry in speed for the wholesale and retail prices. Furthermore, the degree of long-run asymmetry is found much more prominent for the shocks arising from the wholesale level compared to the shocks emerging from the farm level. Overall, given the flexibility and the advantages of the NARDL model relative to the alternative existing methodologies, this study aims at investigating the transmission mechanism between producer and consumer prices in the food sector of EU countries and Turkey.

\section{Data}

Data used in this study are collected through the database of the European Union Statistics Office (Eurostat) and contain consumer and producer food price indices of the selected EU countries (the Netherlands, Italy, Spain, and Poland) and Turkey with 2015 base year. The analysis covers the period between January 2000 and January 2018. Starting date of the estimation sample is dictated by the availability of the producer price index for Turkey. The data used in this study are in used natural logarithmic form and they are seasonally adjusted. ${ }^{1}$

Figure A2 in the appendix depicts the food prices in all countries. It has been observed that all food price series are moving in the same direction and have an increasing trend over time. A visual examination of the series reveals a jump in almost all countries' food prices during the years 2007-2008, which is attributable to the food crises that occurred during those years. 
The selection of the EU countries and Turkey sample is based on the following reasons: First, the Netherlands, Italy, and Spain are selected based on the fact that they are among the top five countries producing the highest agricultural output within the EU-28 countries. ${ }^{2}$ The main reason for the selection of Poland is that it has a high share of agriculture in its national income, similar to Turkey. While agriculture accounts for 2.4 percent of GDP in the EU-28, it accounts for 4.4 percent of GDP in Poland (European Comission, 2017). Since Poland has a considerable amount of agricultural industry output, it is the most subsidized country within the Common Agricultural Policy (CAP) among Non-Euro countries, becoming an EU member after 2004.

Table 1. Zivot-Andrews Unit Root Test Results with One Structural Break

\begin{tabular}{|c|c|c|c|c|c|}
\hline \multirow[b]{2}{*}{ Country } & \multirow[b]{2}{*}{ Variable } & \multicolumn{2}{|c|}{ Level } & \multicolumn{2}{|c|}{ 1st diff. } \\
\hline & & C & $C \& T$ & C & $C \& T$ \\
\hline \multirow{4}{*}{ Turkey } & \multirow{2}{*}{ Icpi } & -3.85 & -4.92 & $-12.57^{* * *}$ & $-12.53 * * *$ \\
\hline & & [2007:02] & [2002:11] & [2003:06] & [2003:06] \\
\hline & \multirow{2}{*}{ Ippi } & -3.65 & -4.22 & $-9.02 * * *$ & $-9.06 * * *$ \\
\hline & & [2008:05] & [2002:11] & [2003:02] & [2006:06] \\
\hline \multirow{4}{*}{ Poland } & \multirow{2}{*}{ Icpi } & -3.22 & -3.18 & $-11.24 * * *$ & $-11.48 * * *$ \\
\hline & & [2007:08] & [2007:08] & [2012:07] & [2003:09] \\
\hline & \multirow{2}{*}{ Ippi } & -3.59 & -4.46 & $-7.70 * * *$ & $-7.78 * * *$ \\
\hline & & [2010:05] & [2010:12] & [2012:10] & [2010:05] \\
\hline \multirow{4}{*}{ Italy } & \multirow{2}{*}{ Icpi } & -3.30 & -3.77 & $-10.79 * * *$ & $-11.00 * * *$ \\
\hline & & [2014:01] & [2007:08] & [2006:05] & [2005:12] \\
\hline & \multirow{2}{*}{ Ippi } & -4.31 & -4.26 & $-7.39 * * *$ & $-7.50 * * *$ \\
\hline & & [2007:04] & [2007:04] & [2008:07] & [2008:07) \\
\hline \multirow{4}{*}{ Spain } & \multirow{2}{*}{ Iсpi } & -2.51 & -4.34 & $-11.32 * * *$ & $-11.31 * * *$ \\
\hline & & [2013:09] & [2008:12] & [2008:07] & [2008:07] \\
\hline & \multirow{2}{*}{ Ippi } & -3.07 & -3.63 & $-7.63 * * *$ & $-7.70 * * *$ \\
\hline & & [2013:07] & [2012:02] & [2008:05] & [2008:02] \\
\hline \multirow{4}{*}{ Netherlands } & \multirow{2}{*}{ Icpi } & -3.73 & -4.09 & $-6.95 * * *$ & $-7.64 * * *$ \\
\hline & & [2003:10] & [2003:10] & [2003:10] & [2004:12] \\
\hline & \multirow{2}{*}{ Ippi } & -3.28 & -3.94 & $-4.80 * *$ & $-4.82^{*}$ \\
\hline & & [2014:05] & [2010:05] & [2012:10] & [2012:11] \\
\hline
\end{tabular}

Note: ${ }^{* * *}$ and ${ }^{* *}$ denote the rejection of the null hypothesis at $1 \%$ and $5 \%$ levels, respectively.

Prior to NARDL estimates, stationarity properties of the variables have been analyzed with unit root tests. The results of Augmented Dickey-Fuller, Phillips and Perron (1988) and KPSS (Kwiatkowski, Phillips, Schmidt, \& Shin, 1992) unit root tests suggest that both producer and consumer food prices are the firstdifference stationary for all countries excluding Turkey. ADF and PP test results suggest that price series for Turkey are I(0), whereas the KPSS test implies that wholesale and consumer prices are integrated of order one $^{3}$. Given the mixed evidence on the stationarity of food price variables for Turkey, stationarity properties of the variables are investigated with the Zivot and Andrews (1992) test under the assumption of an endogenous structural break. Zivot-Andrews test results presented in Table 3 are found to be consistent with their linear counterparts for Poland, Italy, Spain, and the Netherlands. As for Turkey, in contrast with the results of conventional tests both wholesale and consumer food price series are found to have a unit root under the structural break.

\section{Methodology}

Price asymmetry has been investigated with several regime-switching models in the literature: Threshold Error Correction Model (TECM) (Balke \& Fomby, 1997), Markov-Switching Error Correction Model (MSECM) (Psaradakis, Sola, \& Spagnolo, 2004), and Smooth Transition Regression Error Correction Model (STRECM) (Kapetanios, Shin, \& Snell, 2006). Nonlinearity is usually limited to the error correction mechanism in these models, and it may be overly restrictive to conclude that the underlying cointegrating relationship can be interpreted as a linear combination of the underlying non-stationary variables since cointegrating 
relationship may, in general, also be subject to asymmetry or nonlinearity (Shin et al., 2014). Thus, it is necessary to obtain a theoretical model that can reliably integrate asymmetry and nonlinearities in the cointegrating relationship and ECM, as Saikkonen (2008) stated. The NARDL model constructed by Shin et al. (2014) relies on a nonlinear asymmetric cointegration relationship estimated through an ARDL model that is originally developed by and Pesaran, Shin, and Smith (2001) and is modified to integrate asymmetry and nonlinearities in the cointegrating relationship and ECM in this framework.

The main objective of this section is to provide information on the models utilized to analyze the possible asymmetry in the food price transmission channel in both the long and short run. For this purpose, following Shin et al. (2014) before proceeding to the estimation of NARDL, food price transmission channels are estimated via static linear, asymmetric linear, and linear ARDL models to conclude whether it is convenient to analyze the price transmission mechanism through a nonlinear dynamic model. Hence, we start from the following static linear model to examine the relationship between consumer and producer food prices:

$$
\text { lfcpi } i_{t}=\alpha_{0}+\gamma \text { Trend }_{t}+\beta \text { lfppi } i_{t}+u_{t}
$$

where $l f c p i_{t}$ and $l f p p i_{t}$ represent the natural log of consumer and producer food price indices, respectively. Trend $d_{t}$ is the trend variable and $u_{t}$ is an iid error term. After estimation of the static form of the model, the asymmetric effects of producer prices on the consumer prices can be investigated with the following static asymmetric model as in Shin et al. (2014):

$$
l f c p i_{t}=\alpha_{0}+\beta^{+} l f p p i_{t}^{+}+\beta^{-} l f p p i_{t}^{-}+u_{t}
$$

In this setting $l f p p i^{+}$and $l f p p i^{-}$refer to the partial sums of positive and negative changes in the producer food price index they can be computed as lfppi $i_{t}^{+}=\sum_{j=1}^{t} \Delta l f p p i_{j}^{+}=$ $\sum_{j=1}^{t} \max \left(\Delta l f p p i_{j}, 0\right), \quad l f p p i_{t}^{-}=\sum_{j=1}^{t} \Delta l f p p i_{j}^{-}=\sum_{j=1}^{t} \min \left(\Delta l f p p_{j}, 0\right)$. The linear static model described in equation (1) can be transformed into $\operatorname{ARDL}(p, q)$ model to analyze the dynamic long-run relationship between food prices as follows:

$$
\Delta l f c p i_{t}=\alpha_{0}+\rho l f c p i_{t-1}+\theta l f p p i_{t-1}+\sum_{i=1}^{p-1} \gamma_{i} \Delta l f c p i_{t-i}+\sum_{i=0}^{q-1} \pi_{i} \Delta l f p p i_{t-i}+u_{t}
$$

$\operatorname{NARDL}(p, q)$ model proposed by Shin et al. (2014) can be considered as the combination of static asymmetric and linear ARDL $(p, q)$ model and it can be formulated as the following conditional nonlinear ECM.

$$
\begin{aligned}
\Delta l f c p i_{t}=\alpha_{0}+ & \rho l f c p i_{t-1}+\theta^{+} l f p p i_{t-1}^{+}+\theta^{-} l f p p i_{t-1}^{-}+\sum_{j=1}^{p-1} \gamma_{j} \Delta l f c p i_{t-j}+\sum_{j=0}^{q-1}\left(\varphi_{j}^{+} \Delta l f p p i_{t-j}^{+}\right. \\
& \left.+\varphi_{j}^{-} \Delta l f p p i_{t-j}^{-}\right)+\varepsilon_{t}
\end{aligned}
$$

Shin et al. (2014) proposed two tests to investigate the long-run (cointegrating) asymmetric relationship based on the NARDL framework. First, it is important to keep in mind that if $\rho=0$ then Equation (4) turns into a regression including only the first differences. In this case, there exists no long-run relationship between the level values of $y_{t}$ and $x_{t}^{+}$and $x_{t}^{-}$. Therefore, the first test to analyze the presence of long-run relationship, following Banarjee et al. (1998), is based on the t-test, testing the alternative hypothesis $\rho<0$ (cointegration) against the null hypothesis of $\rho=0$ (no cointegration). The second method is the modified F-test proposed by Pesaran et al. (2001) with a null hypothesis of ( $\left.\rho=\theta^{+}=\theta^{-}=0\right)$ (no cointegration) and can be performed regardless of whether the relevant independent variables are I (0) or I (1). These testing procedures rely on the upper and the lower boundaries. If the statistical value of the $t$ and/or $F$ test exceeds the upper bound then the null hypothesis of no cointegration can be rejected. Conversely, if it lies below the 
lower bound then the null hypothesis cannot be rejected. However, if the empirical value of the tests lies between the two critical values, the decision on the long-run relationship is inconclusive.

In case the test results based on Equation (4) favor the presence of short and/or long run asymmetry, dynamic multipliers analyzing the positive and negative effects of unit changes in $\mathrm{lfppi}^{+}$and $\mathrm{lfppi}^{-}$are calculated as follows:

$$
m_{h}^{+}=\sum_{j=0}^{h} \frac{\partial l f c p i_{t+j}}{\partial l f p p i_{t}^{+}}=\sum_{j=0}^{h} \lambda_{j}^{+}, m_{h}^{-}=\sum_{j=0}^{h} \frac{\partial l f c p i_{t+j}}{\partial l f p p i_{t}^{-}}=\sum_{j=0}^{h} \lambda_{j}^{-}, \quad h=0,1,2 \ldots
$$

Long-run dynamic multipliers described above converge to long-run asymmetry coefficients as the horizon increased to infinity, i.e. as $h \rightarrow \infty, m_{h}^{+} \rightarrow \beta^{+}$and $m_{h}^{-} \rightarrow \beta^{-}$. Therefore, dynamic multipliers illustrate and explore the paths and duration of adjustment in the short and long run after a positive or negative shock in regressors. Shin et al. (2014) state that this is a novel feature of the NARDL model since it allows not only to distinguish between short and long-run asymmetry but also a third kind of asymmetry known as adjustment asymmetry. Three types of asymmetry are defined as follows: (i) long-run (reaction) asymmetry $\left(\beta^{+} \neq \beta^{-}\right)$, (ii) short-run (impact) asymmetry $\left(\pi^{+} \neq \pi^{-}\right)$and (iii) adjustment asymmetry derived from the interaction of the first two asymmetries and ECM coefficient of $\rho$.

\section{Empirical Results}

This section presents the estimation results used to analyze possible asymmetric price transmission between the consumer and producer food prices. As stated in the previous section, before the estimation of NARDL, food price transmission channels are analyzed based on the static linear, asymmetric linear, and Linear ARDL models. Hence, our analysis starts with the estimation of the relationship between food prices via a static linear model. Estimation results of the static model are presented in Table 2.

As can be seen, the results imply a positive and statistically significant relationship between consumer and producer prices of food for all countries under consideration. However, $E G_{\text {max }}$ statistics calculated as the largest value of the Engle-Granger residual-based ADF test obtained through the estimation of the static linear model does not corroborate any evidence for the cointegration relationship for all countries.

Table 2. Static Linear Model

\begin{tabular}{cccccccccccc}
\hline & \multicolumn{2}{c}{ Turkey } & \multicolumn{2}{c}{ Poland } & \multicolumn{2}{c}{ Italy } & \multicolumn{2}{c}{ Spain } & \multicolumn{2}{c}{ Netherlands } \\
\hline Var. & Coeff & $\boldsymbol{p}$ & Coeff & $\boldsymbol{p}$ & Coeff & $\boldsymbol{p}$ & Coeff & $\boldsymbol{p}$ & Coeff & $\boldsymbol{p}$ \\
\hline Cons & 0.24 & 0.00 & 0.82 & 0.00 & 2.43 & 0.00 & 0.45 & 0.06 & 3.85 & 0.00 \\
Trend & 0.001 & 0.00 & 0.001 & 0.00 & 0.00 & 0.00 & 0.00 & 0.05 & 0.00 & 0.00 \\
Ifppi & 0.89 & 0.00 & 0.78 & 0.00 & 0.43 & 0.00 & 0.89 & 0.00 & 0.13 & 0.00 \\
\hline$R^{2}$ & 0.99 & \multicolumn{1}{c}{0.98} & \multicolumn{2}{c}{0.98} & 0.95 & \multicolumn{2}{c}{0.90} \\
$\overline{R^{2}}$ & 0.99 & 0.98 & 0.98 & 0.95 & \multicolumn{2}{c}{0.90} \\
$\chi_{s c}^{2}$ & 144.2 & 0.00 & 202.9 & 0.00 & 203.1 & 0.00 & 208.8 & 0.00 & 203.7 & 0.00 \\
$\chi_{h}^{2}$ & 35.00 & 0.00 & 48.85 & 0.00 & 75.60 & 0.00 & 61.01 & 0.00 & 119.9 & 0.00 \\
$\chi_{f f}^{2}$ & 13.49 & 0.00 & 49.02 & 0.00 & 194.1 & 0.00 & 501.6 & 0.00 & 18.57 & 0.00 \\
$\chi_{N}^{2}$ & 1.63 & 0.44 & 34.62 & 0.00 & 9.58 & 0.00 & 6.05 & 0.05 & 1.06 & 0.58 \\
$E G_{\max }$ & -2.96 & \multicolumn{2}{c}{-2.30} & \multicolumn{2}{c}{-2.78} & & -1.87 & \multicolumn{2}{c}{-3.21} \\
\hline
\end{tabular}

Note: $E G_{\max }$ represents the highest value of the Extended Dickey-Fuller test based on Engle-Granger error terms. $E G_{\text {max }}$ values are -3.82 for $5 \%$ significance level and -3.52 for $10 \%$ significance level. Since the series contains an increasing trend, a deterministic trend is included in the model. $\chi_{s c}^{2}, \chi_{h}^{2}, \chi_{f f}^{2}$ ve $\chi_{N}^{2}$ denote the LM test for the serial correlation, the variance test, the functional form test (Ramsey's Reset Test) and the normality test (JB Normality Test) respectively. 
The results of the static nonlinear (asymmetric) model presented in Table 3 are quite similar to that of the static model. In line with the prior expectations, positive changes in producer prices lead to positive changes in consumer prices, while the impact of negative changes varies across the countries. Surprisingly, negative shocks in producer prices lead to increases in consumer prices for Turkey, Italy, and the Netherlands. Moreover, the Wald test results, testing the symmetry of positive and negative changes, corroborate an asymmetry in the food price transmission channel for all countries excluding Spain. $E G_{\max }$ statistics do provide any evidence on the long-run relationship but override the presence of a static asymmetric relationship, emphasizing the importance of dynamic asymmetric relationship.

Table 4 contains the restricted dynamic linear model results estimated through ARDL specification in equation (3). Long-run cointegration coefficients calculated for Turkey, Poland, Italy, Spain, and the Netherlands $\left(L_{y}\right)$ are $1.06,1.28,0.84,0.77$, and 0.44 , respectively, and they are found to be statistically significant. The fact that all long-term coefficients have positive values implies that producer price changes (positive/negative) affect consumer prices in the same direction. However, it is noteworthy that while producer price changes are fully and more than fully transmitted to the consumer prices in Turkish and Polish food markets, the transmission is found to be limited in the other three countries. Those differences in the degree of transmission might be attributed to differences in the market structure and/or concentration rates among the countries (Sexton, 2013; McCorriston, 2014).

Table 3. Static Nonlinear (Asymmetric) Model

\begin{tabular}{|c|c|c|c|c|c|c|c|c|c|c|}
\hline \multirow[b]{2}{*}{ Variable } & \multicolumn{2}{|c|}{ Turkey } & \multicolumn{2}{|c|}{ Poland } & \multicolumn{2}{|c|}{ Italy } & \multicolumn{2}{|c|}{ Spain } & \multicolumn{2}{|c|}{ Netherlands } \\
\hline & Coeff & $p$ & Coeff & $p$ & Coeff & $p$ & Coeff & $P$ & Coeff & $p$ \\
\hline Cons & 2.34 & 0.00 & 4.18 & 0.00 & 4.30 & 0.00 & 4.23 & 0.00 & 4.40 & 0.00 \\
\hline lfppit $i_{t}^{+}$ & 0.94 & 0.00 & 0.88 & 0.00 & 0.60 & 0.00 & 1.01 & 0.00 & 0.23 & 0.00 \\
\hline lfppi $i_{t}^{-}$ & -0.67 & 0.00 & 0.38 & 0.00 & -0.05 & 0.49 & 1.04 & 0.00 & -0.13 & 0.00 \\
\hline$R^{2}$ & \multicolumn{2}{|c|}{0.99} & \multicolumn{2}{|c|}{0.98} & \multicolumn{2}{|c|}{0.97} & \multicolumn{2}{|c|}{0.95} & \multicolumn{2}{|c|}{0.91} \\
\hline$\overline{R^{2}}$ & \multicolumn{2}{|c|}{0.99} & \multicolumn{2}{|c|}{0.98} & \multicolumn{2}{|c|}{0.97} & \multicolumn{2}{|c|}{0.95} & \multicolumn{2}{|c|}{0.91} \\
\hline$\chi_{s c}^{2}$ & 151.93 & 0.00 & 201.05 & 0.00 & 202.20 & 0.00 & 208.50 & 0.00 & 201.61 & 0.00 \\
\hline$\chi_{h}^{2}$ & 34.63 & 0.00 & 67.12 & 0.00 & 118.80 & 0.00 & 103.41 & 0.00 & 118.39 & 0.00 \\
\hline$\chi_{f f}^{2}$ & 16.01 & 0.00 & 28.19 & 0.00 & 313.74 & 0.00 & 354.50 & 0.00 & 15.08 & 0.00 \\
\hline$\chi_{N}^{2}$ & 2.69 & 0.26 & 20.54 & 0.00 & 37.25 & 0.00 & 5.06 & 0.08 & 4.19 & 0.12 \\
\hline$W_{p^{+}}=W_{p^{-}}$ & 166.30 & 0.00 & 285.30 & 0.00 & 181.70 & 0.00 & 0.16 & 0.69 & 159.25 & 0.00 \\
\hline$E G_{\max }$ & \multicolumn{2}{|c|}{-3.04} & \multicolumn{2}{|c|}{-2.55} & \multicolumn{2}{|c|}{-2.87} & \multicolumn{2}{|c|}{-1.85} & \multicolumn{2}{|c|}{-3.66} \\
\hline
\end{tabular}

Note: $E G_{\max }$ represents the highest value of the Extended Dickey-Fuller test based on Engle-Granger error terms. $E G_{\max }$ values are -4.17 for $5 \%$ significance level and -3.87 for $10 \%$ significance level. $\chi_{s c}^{2}, \chi_{h}^{2}, \chi_{f f}^{2}$ and $\chi_{N}^{2}$ refers to LM test, variance test, functional form test (Ramsey Reset Test) and normality test (JB Normality Test) for serial correlation, respectively. $W_{p^{+}}=W_{p^{-}}$test refers to the WALD Test in which the coefficients of $l f p p i_{t}^{+}$and $l f p p i_{t}^{-}$are tested. 


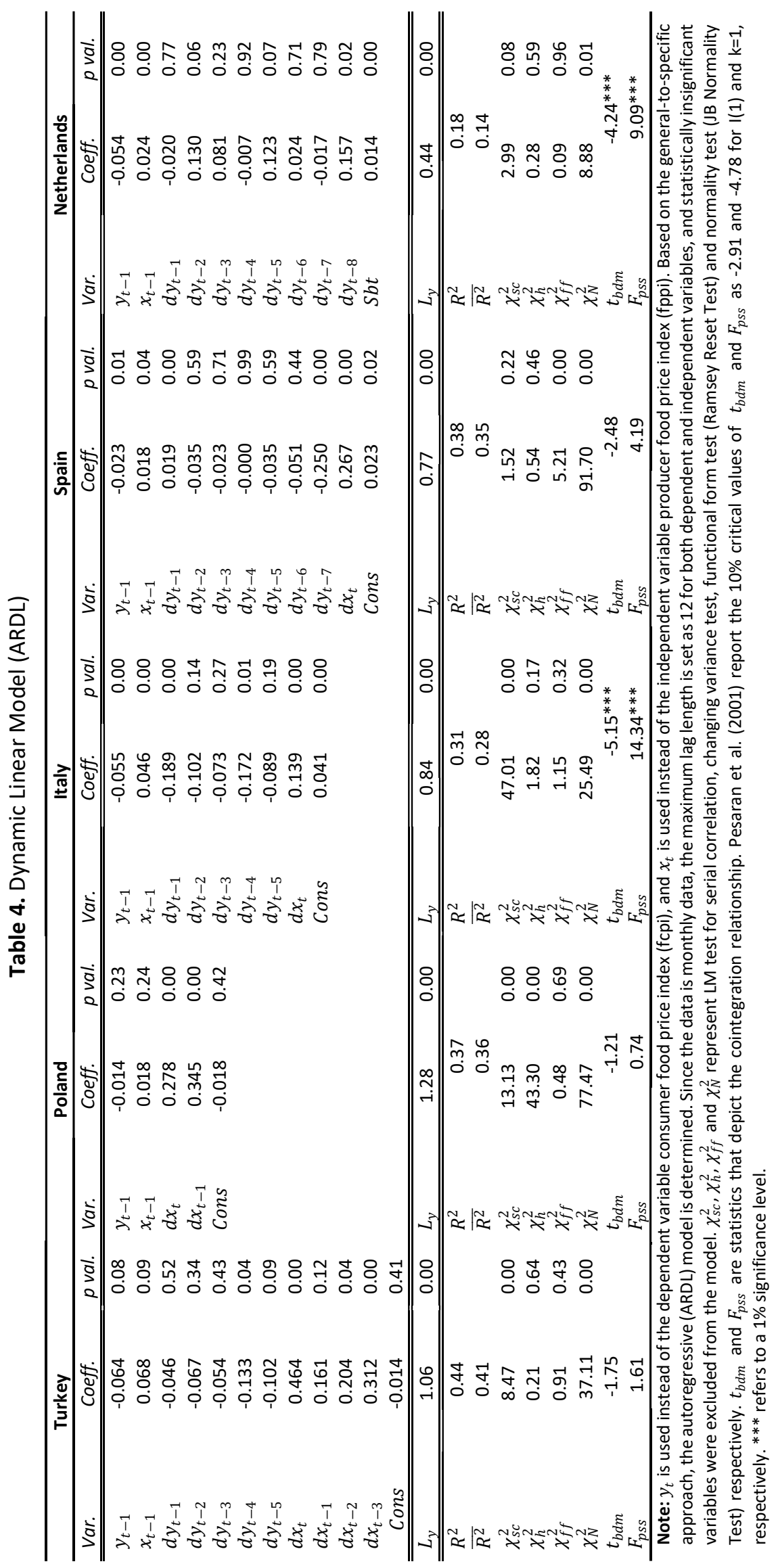




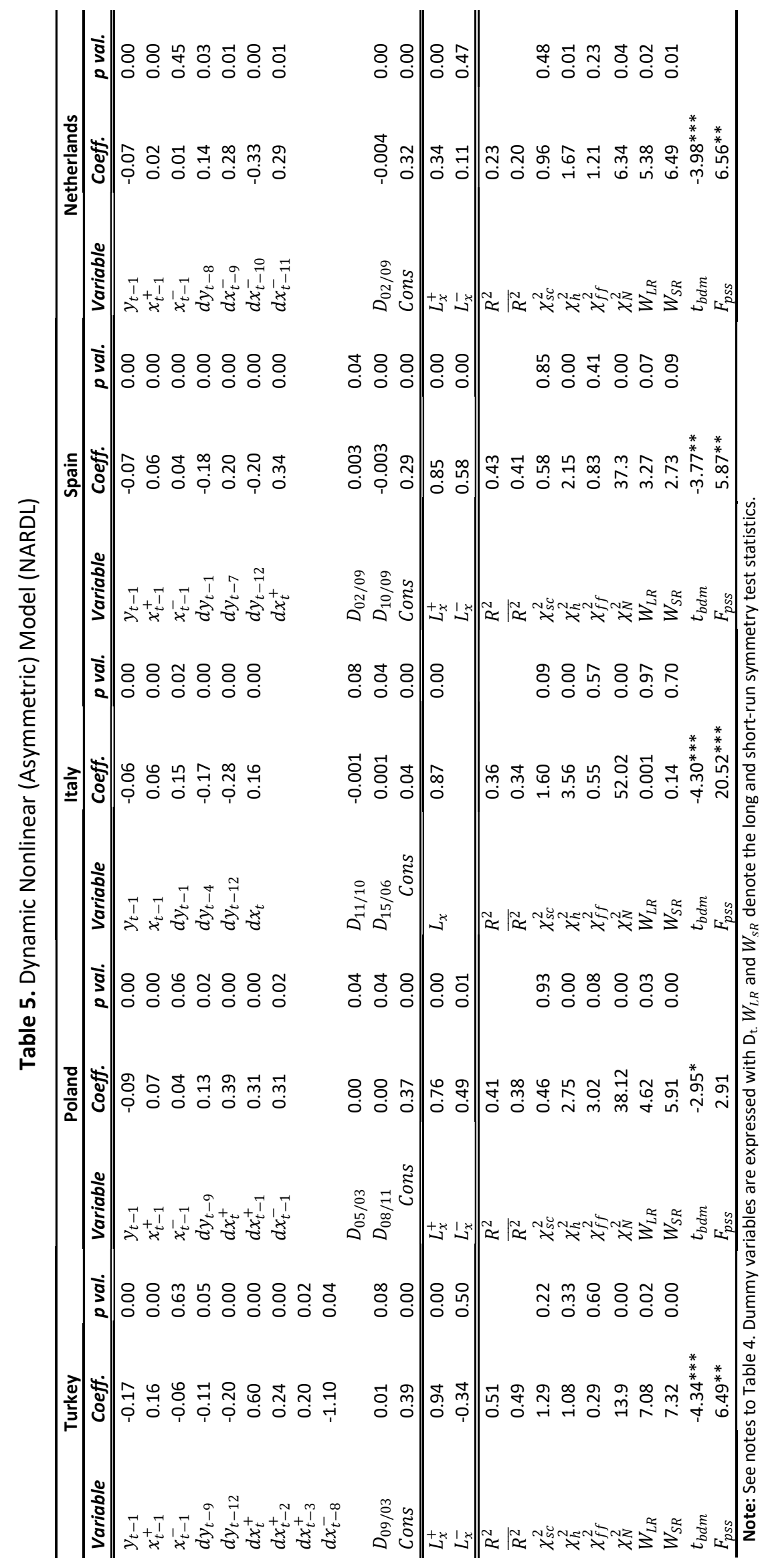


Although long-term coefficients are statistically significant, the point to be prioritized is the statistical significance of the long-term (cointegration) relationship between variables. Also, the statistical significance of the short-term relationship is another important detail. Bounds test results do not provide empirical support for the presence of dynamic and linear cointegration relationship between producer and consumer food prices in Turkey, Poland, and Spain as both $t_{b d m}$ and $F_{p s s}$ statistics are below the critical lower bound values of Pesaran et al. (2001). On the other hand, the test statistics for Italy and the Netherlands indicate the existence of a long-term dynamic and linear relationship.

It should be noted that in the models estimated above, both dynamic and asymmetrical features were not introduced into the models at the same time. In this case, the NARDL model is used to account for both short-term and long-term dynamic asymmetric relationships between consumer and wholesale food prices. Table 5 presents the results of the restricted dynamic asymmetric model estimated through the ARDL method based on the equation (4). The optimal lag length of the NARDL model is determined through a general to specific approach and, the maximum lag lengths are set as $\max q=\max p=12$. Then, the final version of the model is obtained by removing statistically insignificant variables at $10 \%$ significance level. ${ }^{4}$ To account for the effects of regime changes on the long-run relationship, regime dummies based on Bai and Perron's $(1998,2003 a, 2003 b)$ multiple structural break test are introduced as exogenous variables into the NARDL model. ${ }^{5}$ Table 5 shows that the parameters of the regime dummies are statistically significant for the vast majority of countries.

Table 6. Short-Long Run Symmetry Test Results

\begin{tabular}{lccc}
\hline Country & Short-run Relation & Long-run Relation & Result \\
\hline & $H_{o}:$ Symmetric, & $H_{o}:$ Symmetric, & \\
& $\varphi_{j}^{+}=\varphi_{j}^{-}$ & $-\theta^{+} / \rho=-\theta^{-} / \rho$ & \\
& $H_{i}:$ Asymmetric, & $H_{i}:$ Asymmetric, & \\
& $\varphi_{j}^{+} \neq \varphi_{j}^{-}$ & $-\theta^{+} / \rho \neq-\theta^{-} / \rho$ & AA \\
\hline Turkey & $7.08^{* * *}$ & $7.32^{* *}$ & AA \\
Poland & $5.91^{* * *}$ & $4.62^{* * *}$ & SS \\
Italy & 0.14 & 0.001 & AA \\
Spain & $2.73^{*}$ & $3.27^{*}$ & AA \\
Netherlands & $6.49^{* * *}$ & $5.38^{* * *}$ & \\
\hline
\end{tabular}

Note: ${ }^{* *}, * *$ and $*$ denote the rejection of null hypothesis at $1 \%, 5 \%$ and $10 \%$ level, respectively. AA: short-run asymmetric $\&$ longrun asymmetric, SS: short-run symmetric \& long-run symmetric.

The $t_{b d m}$ and $F_{p s s}$ statistics obtained from NARDL models indicate that the null hypothesis of no longrun relation between producer and consumer food prices is rejected in all countries except for Poland. ${ }^{6}$ For the Polish case, the only short-run relationship between producer and consumer food prices is evidenced. Both long-run symmetry test, $\mathrm{W}_{\mathrm{LR}}$, (given by the null hypothesis of $H_{0}:-\theta^{+} / \rho=-\theta^{-} / \rho\left(L_{y}^{+}=L_{y}^{-}\right)$) and short-run symmetry test, $\mathrm{W}_{\mathrm{SR}}$, (given by the null hypothesis of $H_{0}: \varphi_{j}^{+}=\varphi_{j}^{-}$) results indicate that relationship between producer and consumer food prices is not symmetric for all countries excluding Italy. Table 6 is a condensed version of Table 5 that includes the results of symmetry tests for both short and long-run relationships to aid the reader's comprehension. Except for Italy, test results show that price transmission between producer and consumer food prices is asymmetric in the short and long run for Turkish, Polish, Spanish, and Dutch food markets.

In the short and long run, the asymmetric transmission mechanism provides information about the speed and magnitude of the asymmetry. As a result, the test results in Table 5 show that a price shock matters in both speed and magnitude for Turkey, Spain, and the Netherlands because asymmetric price transmission exists in both the short and long run for those countries. This would be the case for Poland if there were a long-run relationship between consumer and producer food prices. However, the significant short-run relationship for Poland indicates that speed asymmetry remains a fact for Polish food markets in terms of 
the price transmission mechanism. For the Italian case, neither asymmetry in speed nor magnitude matters because the price transmission mechanism is symmetric in both the short and long run.

The long-run coefficients for positive producer price changes $\left(L_{x}^{+}\right)$and the negative ones $\left(L_{x}^{-}\right)$for Turkey are obtained as 0.94 and -0.34 (statistically insignificant) respectively which means a $1 \%$ increase in producer prices is almost entirely transmitted to the consumer food prices (see Table 5). Despite the fact that the coefficient for negative changes is statistically insignificant, the transmission elasticity of price increases appears to be 128 percent greater than the transmission elasticity of price decreases, implying a magnitude asymmetry in price transmission. Furthermore, the presence of short-run asymmetry implies the presence of speed asymmetry.

As there is no long-run relationship between producer and consumer food prices in Poland, only a short-run relationship could be interpreted. However, it is worth noting that the gap between downstream and upstream prices is lower than in Turkey and positive, as expected, providing evidence for the asymmetric price transmission mechanism. The sign of the short-term coefficients of both positive and negative producer price changes is consistent with expectations, and no significant difference in the speed of asymmetry is reported.

The difference in price transmission elasticity between positive and negative price shocks in Poland and Turkey is consistent with the theory. This type of long-term asymmetric price transmission is compatible with a convex price transmission function (logarithmic) in prices when market power exists. Azzam (1999) demonstrated that when sellers have market power, the fully concave aggregate demand function favors the fully convex price transmission function. Changes in producer food prices are transmitted to consumer food prices in the Italian food markets via an asymmetric transfer mechanism in both the long and short run. In the case of Italy, a $1 \%$ increase (decrease) in producer prices in the food market results in a $0.87 \%$ increase (decrease) in consumer prices. The positive sign of the coefficient is compatible with the theory.

The long-run coefficients for positive $\left(L_{x}^{+}\right)$and the negative producer price changes $\left(L_{x}^{-}\right)$for Spain is obtained as 0.85 and 0.58 respectively, which means a $1 \%$ increase (decrease) in producer prices leads to a $0.85 \%(0.58 \%)$ increase (decrease) in consumer food prices (see Table 5$)$. In other words, producer food price increases are transmitted to consumer food prices at a high rate while price decreases are transmitted to the consumer food prices almost in half. The transmission elasticity of price increases seems to be $27 \%$ higher than the transmission elasticity of price decreases which implies an asymmetry in magnitude in terms of price transmission. Besides, the existence of short-run asymmetry suggests an asymmetry in speed.

Finally, results for the Netherlands obtained similar to that of Turkey and Spain, indicate that asymmetric price transmission mechanism is valid both in the long-run and short-run. The long-run coefficients for positive producer price changes $\left(L_{x}^{+}\right)$and the negative ones $\left(L_{x}^{-}\right)$for the Netherlands are obtained as 0.34 and 0.11 (statistically insignificant), respectively, which means a $1 \%$ increase in producer prices brings about a $0.34 \%$ increase in consumer food prices (see table 5). However, due to the statistical insignificance of the coefficient for negative producer food price changes, an economic interpretation for Turkey is not possible. Turkey's coefficient is positive, consistent with theory and expectations. Asymmetry in magnitude and speed is also observed, and the transmission elasticity of price increases is found to be greater than that of price decreases by $23 \%$.

After detection of the asymmetric price transmission mechanism in the short and long run, dynamic multipliers which correspond to the unit changes in $l f p p i_{t}^{+}$and $l f p p i_{t}^{-}$are calculated using equation (5). Dynamic multipliers allow us to trace down the evolution of a price at a certain level of the supply chain following a price shock at another level of the supply chain (Fousekis et al., 2016). Dynamic multipliers for price transmission from producer to consumer prices are depicted in Figure 1 for Turkey, Poland, Italy, Spain, and the Netherlands. The dynamic multiplier results for each country sample are generally consistent with the NARDL model results shown in Table 5.

It has been observed that positive producer price shocks almost entirely affect consumer prices. Because negative shocks are statistically insignificant and the asymmetry line moves over the horizontal axis 
with a positive value, we conclude that positive shocks outperform negative shocks in terms of the magnitude of adjustment in the long run. It takes about 24 months to fully adjust to the new equilibrium. The presence of increasing margins between producer and consumer food prices is indicated by the difference in long-run price transmission elasticities of positive and negative price shocks. We find that positive shocks outperform negative ones in terms of adjustment speed because consumer prices react to negative shocks eight months later than positive shocks. This disparity reflects a defect in Turkish food markets in terms of flexibility in the face of positive and negative price shocks.

Given the lack of a long-run cointegrating relationship, only an asymmetric transmission mechanism in the short run is interpreted for Poland. In terms of adjustment speed, we find no discernible difference between positive and negative food producer price shocks because consumer food prices respond instantly to both shocks, but the adjustment process takes slightly longer for negative shocks. As a result, one can conclude that Polish food markets appear to have a flexible structure in terms of short-term price adjustment.

The dynamic multipliers for price transmission from producer to consumer prices in Italian food markets depicted in panel (c) of Figure 1 suggest that consumer food prices respond equally to positive and negative producer food price shocks. It takes about 36 months to fully adjust to the new equilibrium. Following the initial phase of the price shock, one can say that convergence to the long-run equilibrium occurs very slowly. In the short run, consumer prices respond to increases and decreases in producer prices at the same rate. As a result, the results for the dynamic multipliers confirm the symmetric transmission mechanism in both the short and long run for the Italian case.

In the Spanish food market, consumer food prices do not respond at the same rate to positive and negative producer price shocks. We find that positive shocks outperform negative ones in terms of adjustment speed because consumer prices respond to negative shocks six months later than positive shocks. The magnitude of the adjustment for positive producer price shocks exceeds the magnitude of the adjustment for negative producer price shocks; thus, the price adjustment mechanism is asymmetric. It takes about 24 months to fully adjust to the new equilibrium. As in Turkey, the difference in long-run price transmission elasticities of positive and negative price shocks causes increasing margins between producer and consumer food prices.

Panel (e) of Figure 1 depicts dynamic multipliers for price transmission from producer to consumer prices in the Dutch food markets. Negative shocks are statistically insignificant, and the asymmetry line moves over the horizontal axis with a positive value, as in the case of Turkey. In terms of the magnitude of the adjustment, it is thus concluded that positive shocks outnumber negative shocks in the long run. It takes about 36 months to fully adjust to the new equilibrium. Similar to other asymmetric evidence, the difference in long-run price transmission elasticities of positive and negative price shocks highlights the increasing margins between producer and consumer food prices. We find that negative shocks outnumber positive shocks in terms of adjustment speed because consumer prices respond to negative shocks faster than positive shocks. 
Figure 1. Dynamic Multipliers

\section{a. Turkey}

TR

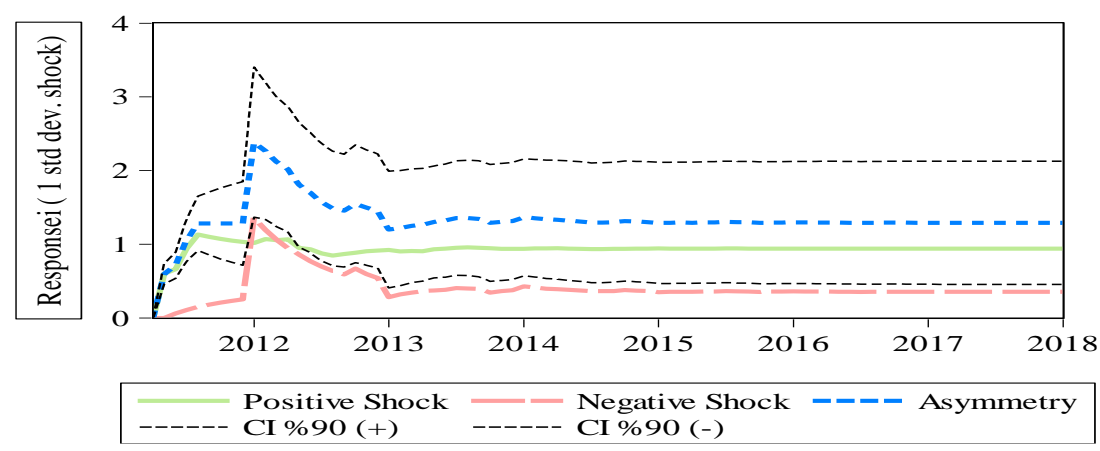

b. Poland

PL

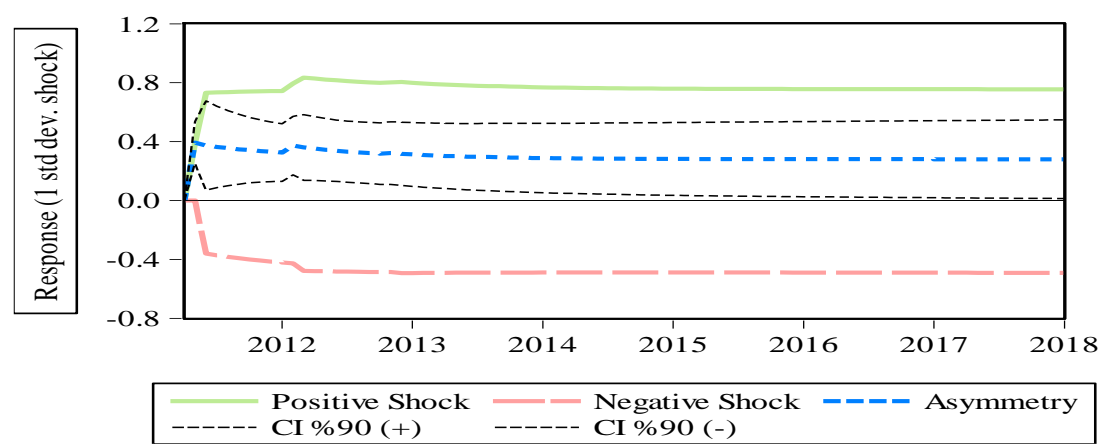

c. Italy

IT

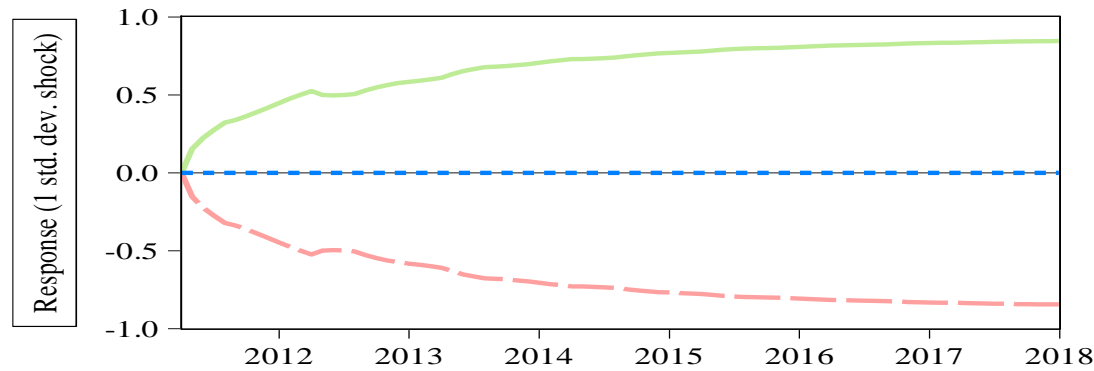

Positive Shock -- Negative Shock ---= Asymmetry 
Figure 1. Dynamic Multipliers (Continued)

\section{d. Spain}

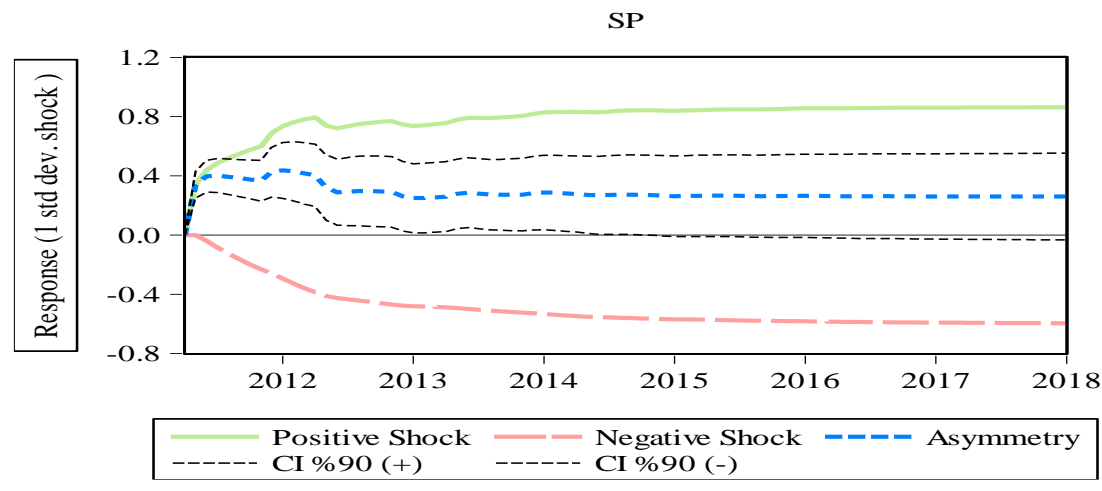

\section{e. The Netherlands}

NI
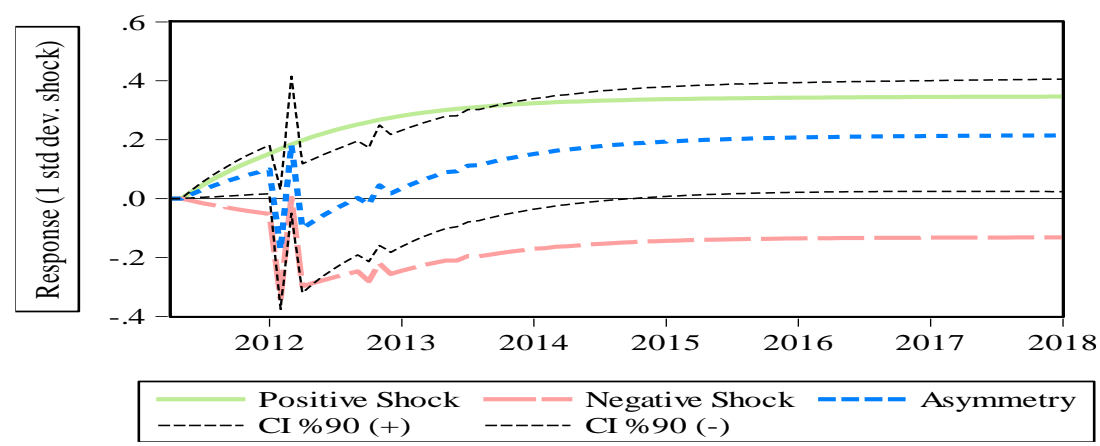

\section{Conclusion}

The main objective of this study is to investigate the functioning of the price transmission mechanism throughout the food supply chain by accounting for the presence of the asymmetric price transmission channel in the food markets of Turkey, Poland, Italy, Spain, and the Netherlands. For this purpose, the asymmetric impact of wholesale food prices on consumer food prices has been investigated with the estimation of the NARDL model.

Empirical results of this study are in line with the proposition of Peltzman (2000) on asymmetric price transmission as a general "rule of the market" rather than an "anomaly" which could be observed randomly as asymmetric price transmission between producer and consumer prices in the food supply chain has been evidenced for all except for Italy. Furthermore, the empirical results of this study are also consistent with the results obtained from the Food Prices Observation Tool created by the European Statistical Institute. According to the observations of this tool, in all EU-28 countries, there is either positive or negative or both positive and negative asymmetric price adjustment in the food markets between producer and consumer prices.

According to Fousekis et al. (2016), asymmetry in speed, i.e. the time of transmission of a positive or negative price shock from one level of the supply chain to other levels of the chain, is eventually transmitted to other levels of the market, albeit at different times and along different paths depending on the sign of the shock. However, when there is magnitude asymmetry as a result of equivalent positive or negative shocks occurring at one stage of the supply chain, prices may not return to the equivalent equilibrium levels at the other stages of the chain. As a result, price margins and interest rates are permanently influenced in the long run. The empirical findings of this study indicate that this is the case for Turkey, Spain, and the Netherlands, 
as asymmetric price transmission has been detected in both the short- and long-run (speed and magnitude) for those countries. As a result, the risk of chronic rates of price margins and price ratios between food processing-retailer and retailer-consumer levels exists in these countries' food markets.

Additionally, when the magnitude of long-run asymmetry is measured in terms of the difference between the positive and negative price transmission elasticity coefficients, it is clear that producers in all three countries gain from price changes that reduce consumer welfare. The argument for this claim is that there is a positive difference between the price transmission elasticity of positive and negative price shocks, implying that increases in producer prices are transmitted to consumer prices more rapidly than decreases. In this context, the highest welfare loss suffered by consumer groups is Turkish, Spanish, and Dutch consumers.

Regarding the level of development, Turkish consumers would suffer a greater loss of welfare than consumers in other countries. Because the percentage of income spent on food consumption is expected to be higher in Turkey, which is less developed than Spain and the Netherlands, and the higher the percentage of income spent on food, the greater the negative impact on consumer welfare caused by price shocks. As a result, Turkey will suffer more because the long-run relationship has not been verified; only the speed of asymmetry matters for Polish food markets.

The evidence on asymmetric price transmission mechanisms can be explained by the imperfectly competitive structure of food markets due to a high degree of concentration (Sexton, 2013; McCorriston, 2014) or the increased influence of private label products (Mills, 1995; Gabrielsen \& Srgard, 2007). These intriguing topics are beyond the scope of this article, but they can be considered a venue for further research as firm-level data becomes available.

\section{Declarations and Disclosures}

Ethical Responsibilities of Authors: The authors of this article confirm that their work complies with the principles of research and publication ethics.

Conflicts of Interest: No potential conflict of interest was reported by the authors.

Funding: The authors received no financial support for the preparation and/or publication of this article.

Author Contributions: The authors confirm contribution to the article as follows: Conceptualization and design, $\mathrm{O}$. Kandemir Kocaaslan, A. N. Catik, and A. Kat; data collection, A. Kat; analysis of data and interpretation of results, A. N. Catik and A. Kat; writing the first draft of the manuscript, O. Kandemir Kocaaslan and A. Kat; review and editing, A. N. Catik and A. Kat. The manuscript/article was read and approved by all the authors, and all authors accepted responsibility for their article.

Plagiarism Checking: This article was screened for potential plagiarism using a plagiarism screening program.

\section{Endnotes}

1. Seasonal adjustment of the time series is carried out through Census $X-13$ (SA) analysis.

2. Since the UK is in the process of "Brexit", it is removed from the rankings and thus the Netherlands is ranked among the top five countries (Euro 5). For detailed information, see. EU Commission, Statistical Information Note, 2017.

3. The results of linear unit root tests are not presented here but are available upon request from the corresponding author.

4. The results of the test presented in Tables $A 1$ and A2 in the appendix indicate the presence of at least one significant structural break for all countries.

5. The stability of the estimated models has been examined through cumulative sums (CUSUM) tests. The results of the tests presented in Figure A1 in the appendix for each country indicate that the estimated NARDL models do not have any serious parameter instability problem. 


\section{References}

Abdulai, A. (2002). Using threshold cointegration to estimate asymmetric price transmission in the Swiss pork market. Applied Economics, 34, 679-687.

Aramyan, L., \& Kuiper, M. (2009). Analyzing price transmission in agri-food supply chains: An overview. Measuring Business Excellence, 13, 3-12.

Awokuse, T., \& Wang, X., (2009), Threshold effects and asymmetric price adjustments in US dairy markets. Canadian Journal of Agricultural Economics, 57(2), 269-286.

Azzam, A. M. (1999). Asymmetry and rigidity in farm-retail price transmission. American Journal of Agricultural Economics, 81, 525-533.

Bai, J., \& Perron, P. (1998). Estimating and testing linear models with multiple structural changes. Econometrica, 66, 4778.

Bai, J., \& Perron, P. (2003a). Computation and analysis of multiple structural change models. Journal of Applied Econometrics, 18, 1-22.

Bai, J., \& Perron, P. (2003b). Critical values for multiple structural change tests. Econometrics Journal, 6, 72-78.

Balcombe, K., Bailey, A., \& Brooks, J. (2007). Threshold effects in price transmission: The case of Brazilian wheat, maize, and soya prices. American Journal of Agriculture Economics, 89, 308-323.

Barassi, M. R., \& Ghoshray, A. (2007). Structural change and long-run relationship between US and EU wheat export prices. Journal of Agricultural Economics, 58, 76-90.

Ben-Kaabia, M., \& Gil, J. M. (2007). Asymmetric price transmission in the Spanish lamb sector. European Review of Agricultural Economics, 34(1), 53-80.

Boyd, M. S., \& Brorsen, B. W. (1988). Price asymmetry in the US pork marketing channel. North Central Journal of Agricultural Economics, 10, 103-110.

Capps Jr., O., \& Sherwell, P. (2005). Spatial asymmetry in farm-retail price transmission associated with fluid milk products. Selected paper prepared for presentation at the American agricultural economics association annual meeting, Providence, Rhode Island, July 24-27, 2005.

Delatte, A. L., \& Lopez-Villavicencio, A. (2012). Asymmetric exchange rate pass-through: Evidence from major countries. Journal of Macroeconomics, 34(3), 833-844.

European Commission, (2012). Study on price transmission in the sugar sector, Final Report. European Commission, DG Agriculture, and Rural Development, TENDER N ${ }^{\circ}$ AGRI-2011-EVAL-03. Retrieved October, 2012, from https://ec.europa.eu/agriculture/sites/agriculture/files/external-studies/2012/sugar-price transmission/fulltext_en.pdf

European Commission, (2017). Statistical Factsheet, June 2017. Retrieved from June 2017, http://ec.europa.eu/agriculture/statistics/factsheets/pdf/be_en.pdf

Fousekis, P., Katrakilidis, C., \& Trachanas, E. (2016). Vertical price transmission in the US beef sector: Evidence from the nonlinear ARDL model. Economic Modelling, 52(PB), 499-506.

Gabrielsen, T. S., \& Sørgard, L. (2007). Private labels, price rivalry, and public policy. European Economic Review, 51, 403-424.

Ghoshray, A. (2002). Asymmetric price adjustment and the world wheat market. Journal of Agricultural Economics, 53(2), 299-317.

Gomez, M. I., \& Koerner, J. (2009). Do retail coffee prices increase faster than they fall? Asymmetric price transmission in France, Germany, and the United States. Working Papers 55930, Cornell University, Department of Applied Economics and Management.

Gonzalo, J., \& Pitarakis, J. Y. (2005). Threshold effects in multivariate error correction models. Handbook of Econometrics 1.

Goodwin, B. K., \& Harper, D. C. (2000). Price transmission, threshold behavior, and asymmetric adjustment in the US pork sector. Journal of Agricultural and Applied Economics, 32, 543-553.

Goodwin, B. K., \& Piggott, N. (2001). Spatial market integration in the presence of threshold effects. American Journal of Agricultural Economics, 83, 302-317.

Goodwin, B. K., \& Vavra, P. (2005). Analysis of price transmission along the food chain. OECD Food, Agriculture and Fisheries Working Papers No. 3, OECD. 
Is There Any Asymmetry Between Wholesale and Consumer Food Prices in Selected European Countries and Turkey?

Greenwood-Nimmo, M., \& Shin, Y. (2013). Taxation and the asymmetric adjustment of selected retail energy prices in the UK. Economics Letters, 121(3), 411-416.

Greenwood-Nimmo, M., Shin, Y., \& van Treeck, T. (2013). The decoupling of monetary policy from long-term interest rates in the US and Germany. Retrieved October 4, 2013, from https://papers.ssrn.com/sol3/papers.cfm?abstract_id=1894621

Houck, J. P. (1977). An approach to specifying and estimating non-reversible functions. American Journal of Agricultural Economics, 59, 570-572.

Katrakilidis, C., \& Trachanas, E. (2012). What drives housing price dynamics in Greece? New evidence from asymmetric ARDL cointegration. Economic Modelling, 29(4), 1064-1069.

Kwiatkowski, D., \& Phillips, P. C. B., \& Schmidt, P., \& Shin, Y. (1992). Testing the null hypothesis of stationarity against the alternative of a unit root: How sure are we that economic time series have a unit root? Journal of Econometrics, 54(1-3), 159-178.

McCorriston, S. (2014). Competition in the food chain (Working Paper). Transparency of food pricing, EU 7th framework programme. Devon, UK: TRANSFOP.

Meyer, J., \& von Cramon-Taubadel, S. (2004). Asymmetric price transmission: A survey. Journal of Agricultural Economics, 55(3), 581-611.

Mills, D. E. (1995). Why retailers sell private labels. Journal of Economics and Management Strategy, 4, 345-370.

OECD, (2014). OECD Competition Policy Roundtables: Competition Issues in the Food Chain Industry. Retrieved May 15, 2014, from https://www.oecd.org/daf/competition/CompetitionlssuesintheFoodChainlndustry.pdf

OECD, (2015). Food price formation. OECD, 7th food chain analysis network meeting. Trade and Agricultural Directorate. Retrieved October, 2015, from http://www.oecd.org/site/agrfcn/meetings/agrfcn-7-food-price-formationpaperoctober-2015.pdf

Peltzman, S. (2000). Prices rise faster than they fall. Journal of Political Economy, 108, 466-502.

Pesaran, M. H., Shin, Y., \& Smith, R. J. (2001). Bounds testing approaches to the analysis of level relationships. Journal of Applied Economics, 16(3), 289-326.

Phillips, P. C. B., \& Perron, P. (1988). Testing for a unit root in time series regression. Biometrika, 75, 335-346.

Rezitis, A.N., \& Stavropoulos, K. S. (2011). Price transmission and volatility in the Greek broiler sector: A threshold cointegration analysis. Journal of Agricultural \& Food Organization, 9(1), Article 8.

Sexton, R. J. (2013). Market power, misconceptions, and modern agricultural markets. American Journal of Agricultural Economics, 95, 209-219.

Shin, Y., Yu, B., \& Greenwood-Nimmo, M. (2014). Modeling asymmetric cointegration and dynamic multipliers in a nonlinear ARDL framework. In: W.C. Horrace \& R.C. Sickles (Ed.), Festschrift in honor of Peter Schmidt: Econometric methods and applications (pp. 281-314). New York: Springer Science and Business Media.

Thompson, S. R., Sul, D., \& Bohl, M. T. (2002). Spatial market efficiency and policy regime change: Seemingly unrelated error correction model estimation. American Journal of Agriculture Economics, 84(4), 1042-1053.

Tweeten, L. G., \& Quance, C. L. (1969). Positivistic measures of aggregate supply elasticities: Some new approaches. American Journal of Agricultural Economics, 51(2), 342-352.

Varga, T. (2007). Vertical price transmission between market operators in Hungarian agricultural product chains. Studies in Agricultural Economics, 106, 41-70.

Von Cramon-Taubadel, S., \& Fahlbusch, S. (1994). Identifying asymmetric price transmission with error correction models. Poster Session EAAE European Seminar in Reading.

Von Cramon-Taubadel, S., \& Loy, J. P. (1996). Price asymmetry in the international wheat market: Comment. Canadian Journal of Agricultural Economics, 44, 311-317.

Von Cramon-Taubadel, S. (1998). Estimating asymmetric price transmission with the error correction representation: An application to the German pork market. European Review of Agricultural Economics, 25, 1-18.

Ward, R. W. (1982). Asymmetry in retail, wholesale, and shipping point prices for fresh fruits and vegetables. American Journal of Agricultural Economics, 62, 205-212.

Wolffram, R. (1971). Positivistic measures of aggregate supply elasticities: some new approaches- some critical notes. American Journal of Agricultural Economics, 53, 356-359.

Zivot, E., \& Donald, W. K. A. (1992). Further evidence on the great crash: The oil price shock and the unit-root hypothesis. Journal of Business and Economic Statistics, 10(3), 251-270. 


\section{Appendix}

Table A1. Bai-Perron Multiple Structural Break Tests and Hypothesis

\begin{tabular}{lll}
\hline Proposed Test & Null Hypothesis & Alternative Hypothesis \\
\hline $\sup F_{T}(k)$ & $H_{0}:$ No break & $H_{1}:$ Fixed number of breaks \\
$U D_{\max }, W D_{\max }$ & $H_{0}:$ No break & $H_{1}:$ Unknown number of breaks \\
$\sup F_{T}(l+1 / l)$ & $H_{0}: l$ breaks & $H_{1}: l+1$ breaks \\
\hline
\end{tabular}

Source: Bai and Perron, 2003a.

Table A2. Bai-Perron Multiple Break Test Results

Specification

$$
y_{t}=\{\operatorname{lnfcpi}\}, z_{t}=\{1, \operatorname{lnfppi}\}, q=1, p=0, h=26, M=5, \varepsilon=0.15
$$

\begin{tabular}{|c|c|c|c|c|c|}
\hline Statistic & Turkey & Poland & Italy & Spain & Netherlands \\
\hline $\sup F_{T}(1)$ & $136.1^{* *}$ & $196.72 * *$ & $113.76 * *$ & $249.92 * *$ & $35.81^{* *}$ \\
\hline $\sup F_{T}(2)$ & $107.9 * *$ & $178.31^{* *}$ & $161.54 * *$ & $255.30 * *$ & $51.91 * *$ \\
\hline $\sup F_{T}(3)$ & $89.5^{* *}$ & $170.98 * *$ & $219.55^{* *}$ & $285.05^{* *}$ & $66.86 * *$ \\
\hline $\sup F_{T}(4)$ & $78.5^{* *}$ & $137.94 * *$ & $195.08 * *$ & $315.78^{* *}$ & $70.90 * *$ \\
\hline $\sup F_{T}(5)$ & $63.6^{* *}$ & $113.89 * *$ & $159.68^{* *}$ & $276.65^{* *}$ & $79.39 * *$ \\
\hline$U D_{\max }$ & $272.3^{* *}$ & $393.44 * *$ & $439.11 * *$ & $631.57^{* *}$ & $158.79 * *$ \\
\hline$W D_{\max }$ & $272.3^{* *}$ & $469.19 * *$ & $626.19 * *$ & $1084.8^{* *}$ & $311.34 * *$ \\
\hline $\sup F_{T}(1 \mid 0)$ & $136.1^{* *}$ & $196.72 * *$ & $113.76^{* *}$ & $249.92 * *$ & $35.81^{* *}$ \\
\hline $\sup F_{T}(2 \mid 1)$ & $35.5^{* *}$ & $55.98 * *$ & $101.72 * *$ & $96.12^{* *}$ & $51.15^{* *}$ \\
\hline $\sup F_{T}(3 \mid 2)$ & $17.9 * *$ & $35.99 * *$ & $83.36^{* *}$ & $80.60 * *$ & $49.26 * *$ \\
\hline $\sup F_{T}(4 \mid 3)$ & $13.4^{* *}$ & 0.00 & $12.29 * *$ & $8.22 * *$ & $28.26 * *$ \\
\hline $\sup F_{T}(5 \mid 4)$ & 0.3 & n.a. & 0.00 & 0.00 & $10.99 * *$ \\
\hline \multicolumn{6}{|c|}{ Number of Breaks } \\
\hline Schwarz & 4 & 3 & 4 & 5 & 5 \\
\hline$L W Z$ & 3 & 3 & 4 & 4 & 5 \\
\hline Sequential & 5 & 5 & 5 & 5 & 5 \\
\hline \multicolumn{6}{|l|}{ Break Dates } \\
\hline$T_{1}$ & $2003 / 03$ & $2005 / 03$ & $2004 / 08$ & $2002 / 09$ & $2002 / 09$ \\
\hline$T_{2}$ & $2006 / 05$ & 2008/11 & $2008 / 11$ & $2007 / 10$ & 2005/08 \\
\hline$T_{3}$ & $2009 / 03$ & 2013/07 & $2011 / 10$ & 2010/09 & 2008/05 \\
\hline$T_{4}$ & 2014/09 & n.a. & 2015/06 & 2015/06 & 2012/02 \\
\hline$T_{5}$ & n.a. & n.a. & n.a. & n.a. & 2015/06 \\
\hline
\end{tabular}


Figure A1. CUSUM Tests on NARDL Models

(a) Turkey

CUSUM plot with $95 \%$ C.I. (TR)

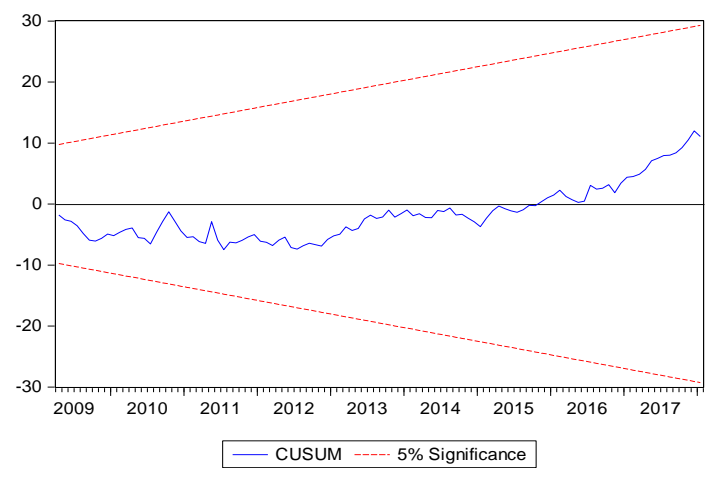

(c) Italy

CUSUM plot with $95 \%$ C.I. (IT)

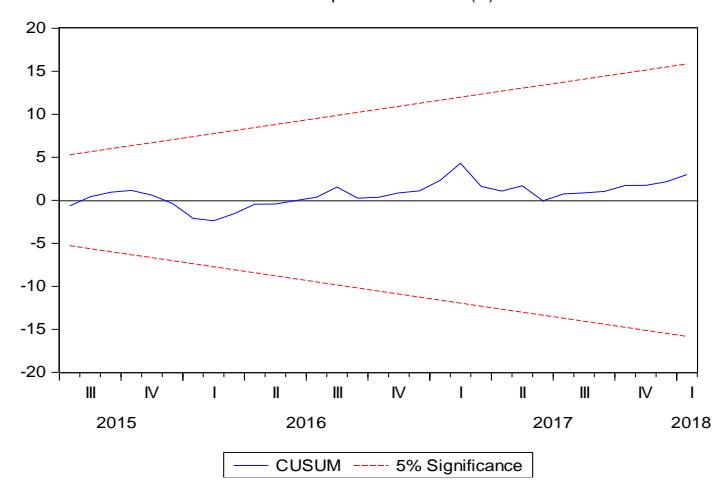

(b) Poland

CUSUM plot with $95 \%$ C.I. (PL)

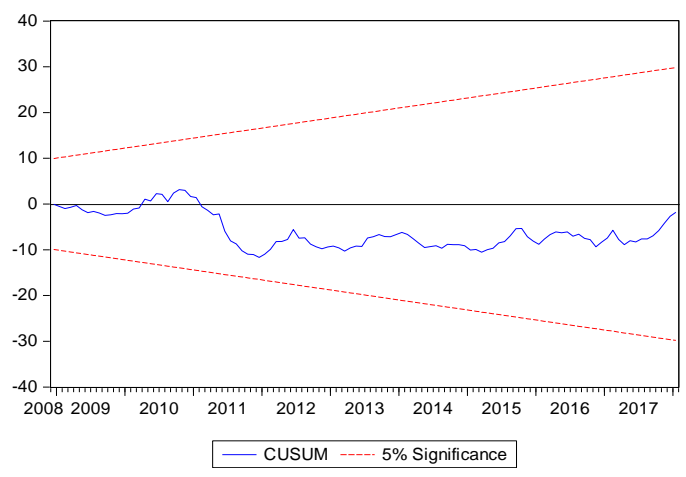

(d) Spain

CUSUM plot with $95 \%$ C.I. (SP)

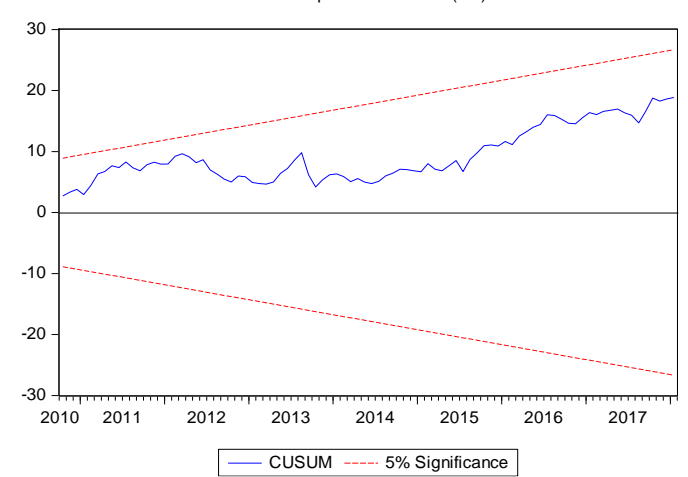

(e) The Netherlands

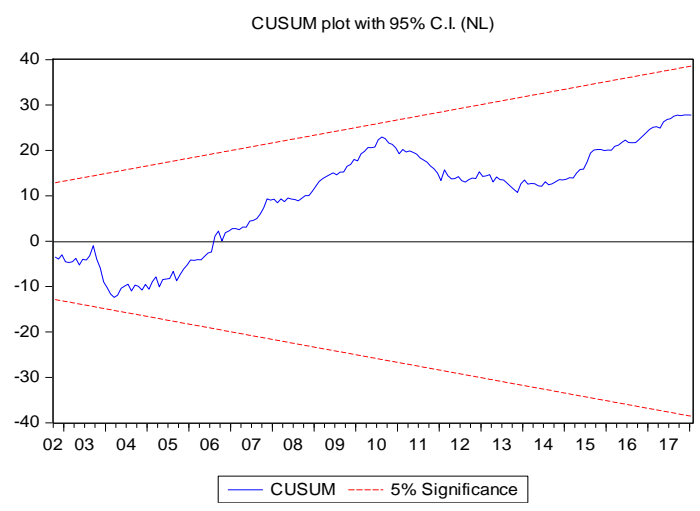


Figure A2. Food Price Indices
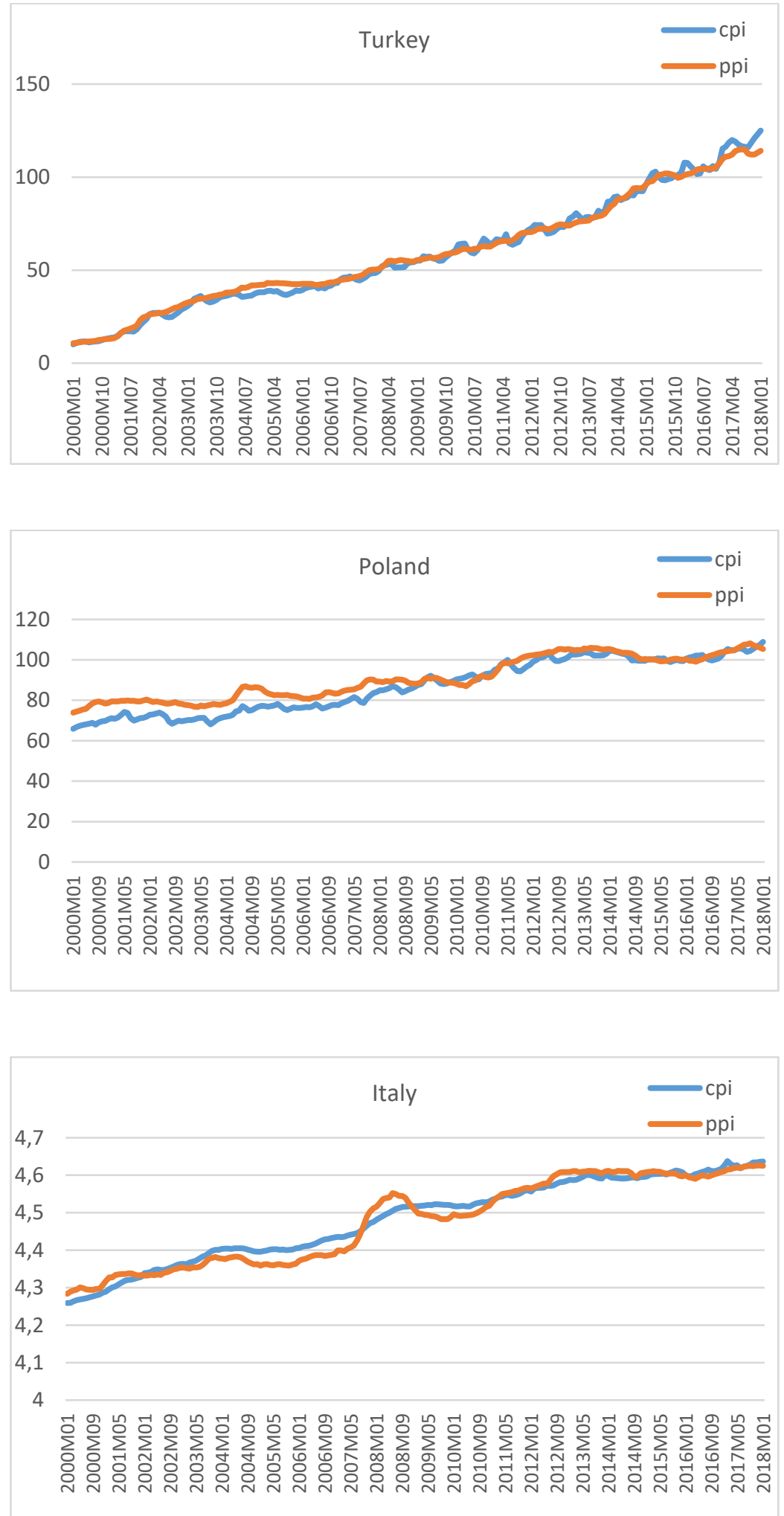

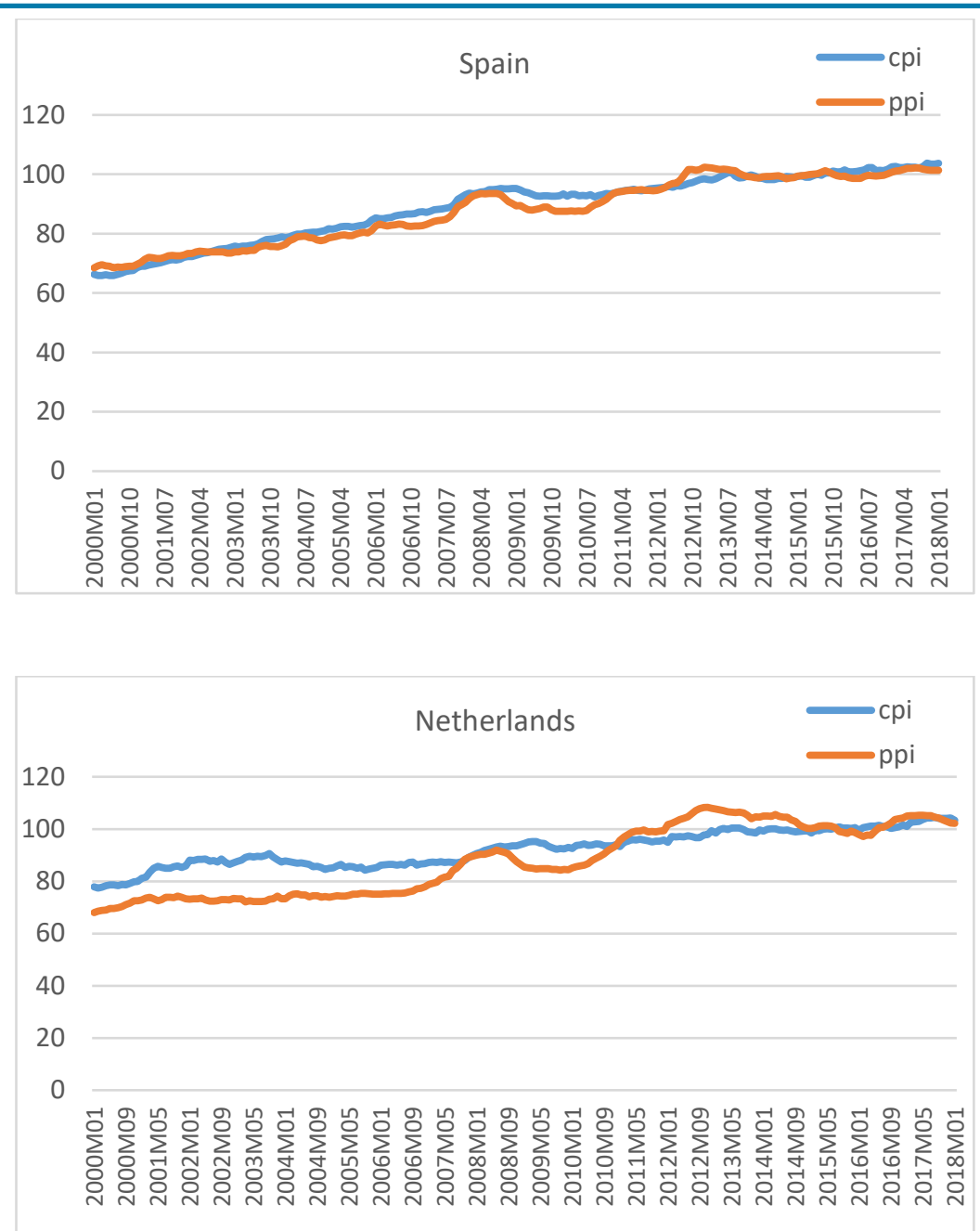